\title{
Range-wide decline of Chinese giant salamanders Andrias spp. from suitable habitat
}

\author{
Benjamin Tapley, Samuel T. Turvey, Shu Chen, Gang Wei, Feng Xie \\ Jian Yang, Zhiqiang Liang, Haifeng Tian, Minyao Wu, Sumio Okada \\ Jie Wang, Jingcai Lü, Feng Zhou, Jingcheng Xu, Haipeng Zhao \\ Jay Rediond, Thomas Brown and Andrew A. Cunningham
}

\begin{abstract}
Over recent decades, Chinese giant salamanders Andrias spp. have declined dramatically across much of their range. Overexploitation and habitat degradation have been widely cited as the cause of these declines. To investigate the relative contribution of each of these factors in driving the declines, we carried out standardized ecological and questionnaire surveys at 98 sites across the range of giant salamanders in China. We did not find any statistically significant differences between water parameters (temperature, dissolved oxygen, ammonia, nitrite, nitrate, salinity, alkalinity, hardness and flow rate) recorded at sites where giant salamanders were detected by survey teams and/or had been recently seen by local respondents, and sites where they were not detected and/or from which they had recently been extirpated. Additionally, we found direct and indirect evidence that the extraction of giant salamanders from the wild is ongoing, including within protected areas. Our results support the hypothesis that the decline of giant salamanders across China has been primarily driven by overexploitation. Data on water parameters may be informative for the establishment of conservation breeding programmes, an initiative recommended for the conservation of these species.
\end{abstract}

Benjamin TAPLeY (Corresponding author, (1) orcid.org/0000-0002-9787-3793), Samuel T. Turvey, Shu Chen, Jay Redbond*, Thomas Brown and Andrew A. Cunningham Zoological Society of London, Regent's Park, London, NW1 4RY, UK. E-mail ben.tapley@zsl.org

Feng XIE and Jie Wang Chengdu Institute of Biology, Chinese Academy of Sciences, Chengdu, China

JiNGCHENG XU College of Life and Environment Sciences, Huangshan University, Huangshan, China

GANG WeI and JingCAI LÜ Guiyang University, Guiyang, China

JIAN YANG Guangxi Teachers Education University, Nanning, China

Haifeng Tian Yangtze River Fisheries Research Institute, Wuhan, China

ZhiQiang Liang Hunan Fisheries Research Institute, Changsha, China

Minyao Wu and Feng Zhou Shaanxi Normal University, Xi'an, China

Sumio OKada Totorri University, Koyama-Minami, Tottori, Japan

HaIPeng Zhao Henan University, Kaifeng, China

${ }^{*}$ Also at: Wildfowl \& Wetlands Trust, Slimbridge, Gloucester, UK

Received 17 February 2020. Revision requested 7 April 2020.

Accepted 7 May 2020. First published online 24 February 2021.
Keywords Amphibian, Andrias, China, conservation, local ecological knowledge, overexploitation, population decline, water chemistry

Supplementary material for this article is available at doi.org/10.1017/So030605320000411

\section{Introduction}

mphibians are the most threatened vertebrate class, with $1_{41 \%}$ of assessed species in danger of extinction (IUCN, 2020). They are threatened by multiple processes that may act synergistically to drive population declines. One of the most significant threats is habitat loss (Gallant et al., 2007). However, some amphibian species have disappeared from intact or suitable habitats (Daszak et al., 1999; Hirschfeld et al., 2016), with such declines usually having been mediated by disease (Skerratt et al., 2007; Stegen et al., 2017) or related to overexploitation (Stuart et al., 2006; Phimmachak et al., 2012).

The Chinese giant salamander is a Critically Endangered aquatic cryptobranchid salamander. It has been identified as a global priority for conservation based on the evolutionary distinctiveness of its so-called living fossil lineage (Gumbs et al., 2018), and was designated as a State 2 protected animal in China in 1998, with this national legislation making hunting illegal (Liang et al., 2004). It has traditionally been interpreted as the single geographically wide-ranging species Andrias davidianus, distributed across multiple montane ecoregions and river basins (Yangtze, Yellow, Pearl, and south-east river drainages), but has recently been shown to constitute a complex of at least three species, including the South China giant salamander A. sligoi and other undescribed taxa (Yan et al., 2018; Liang et al., 2019; Turvey et al., 2019). Giant salamanders were formerly widespread over much of China (Liang et al., 2004; Fei et al., 2006), but in recent decades many populations have undergone dramatic declines or extirpations (Turvey et al., 2018), even in habitats that appear suitable and support abundant prey (Tapley et al., 2015). The range-wide decline of giant salamanders across China has been attributed to overexploitation for the luxury food market (Liang et al., 2004; Wang et al., 2004; Feng et al., 2007; Dai et al., 2009; Cunningham et al., 2016; Turvey et al., 2018), and to habitat loss and 
degradation through anthropogenic modification of freshwater habitats, including through pollutant emissions and the alteration of flow regimes and water turbidity from damming (e.g. Liang et al., 2004; Wang et al., 2004; Dai et al., 2009). However, there has been no systematic attempt to determine the extent to which these two threat processes have each contributed to giant salamander declines in China. This limitation is compounded by a general lack of published data on the habitat requirements of giant salamanders in China, especially with regard to water parameters.

Using environmental data associated with historical locality records, Chen et al. (2018) developed a habitat suitability model for Chinese giant salamanders based on elevation, forest cover, mean annual temperature and mean annual precipitation, which was broadly congruent with the estimated IUCN range map for Andrias davidianus (Liang et al., 2004). Anecdotally, Chinese giant salamanders are thought to inhabit clear, cool, slow to swift flowing streams of $\mathrm{pH} 6-7$ in steep-sided, well-vegetated valleys that have caves in rocky banks (Wang et al., 2004). Water parameters, such as dissolved oxygen, alkalinity and nitrate, are among the known predictors of cryptobranchid salamander distribution in the USA (Pugh et al., 2016). Siltation is known to cause the loss of specific cryptobranchid microhabitats by embedding boulders (under which these salamanders find refugia) in stream substrate (Fobes, 1995); turbidity could therefore be an additional predictor of suitable habitat for cryptobranchid salamanders (Quinn et al., 2013). Water temperature (Buckley \& Jetz, 2007; Grant et al., 2014), pH (Freda \& Dunson, 1986; Grant et al., 2014), ammonia concentration (Weyrauch \& Grubb, 2004), and flow rate (Welsh \& Olivier, 1998) are known to influence the distribution and/or survivorship of all life stages of other salamander species.

Robust understanding of the microhabitat requirements of Chinese giant salamanders and of the drivers of their decline in China is essential if appropriate conservation strategies are to be formulated and implemented. We therefore gathered a novel large-scale dataset during a multi-year field survey programme in China, obtaining data from both ecological surveys and community-based surveys of local ecological knowledge. Together, these multidisciplinary and independent data provide an important new baseline for understanding Chinese giant salamander microhabitat requirements, and for identifying the significance of habitat degradation and/or overexploitation as the primary drivers of population declines across their range.

\section{Methods}

We randomly selected 50 Chinese counties containing historical giant salamander records (Fei et al., 2006), and 50 further counties from a sample of all counties lacking historical records that contained $>50 \%$ predicted suitable

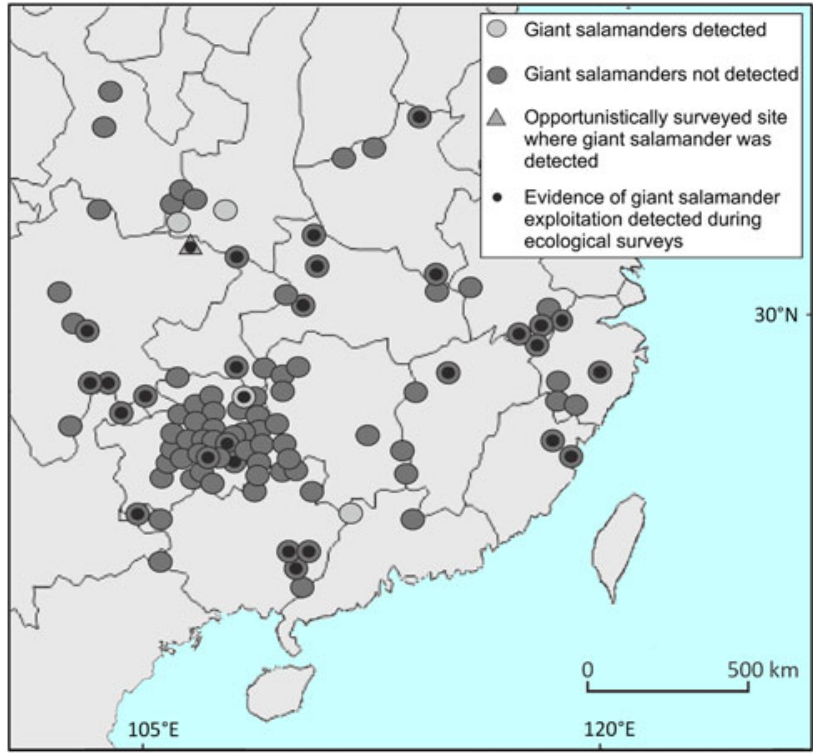

FIG. 1 Sites in China surveyed for Chinese giant salamanders Andrias spp., with sites where salamanders were detected and not detected, the opportunistic survey site where a giant salamander was detected, and sites where direct evidence of giant salamander exploitation was detected.

giant salamander habitat based on the habitat suitability model of Chen et al. (2018). These sites were distributed across 16 Chinese provinces or equivalent administrative units (Fig. 1; Supplementary Table 1). We selected sites with intact natural habitat (i.e. fast-flowing mountain streams with riparian forest cover and rocky substrates) for surveys in all counties, with specific site selection for those most likely to be occupied by Chinese giant salamanders determined through discussion with local government fisheries offices or protected area managers. Logistical issues prevented survey work in three of the randomly selected counties, so only 97 of the 100 selected sites were surveyed. In addition, we opportunistically surveyed an additional site within GuangwushanNuoshuihe Geopark National Nature Reserve in Nanjiang County, Sichuan Province, which contained $>50 \%$ predicted suitable habitat and had recent reports of giant salamanders.

Fieldwork was conducted during $2013-2016$ by teams trained to undertake standardized field survey methodology (Tapley et al., 2017), with surveys during May-October each year to coincide with inferred peak activity periods of Chinese giant salamanders (Okada et al., 2008). Ecological surveys covered a cumulative $1 \mathrm{~km}$ transect of suitable habitat at each site. At some sites, geographical barriers (e.g. waterfalls) prevented the completion of a continuous $1 \mathrm{~km}$ transect; in such cases, the survey team continued the survey beyond the obstruction until a cumulative transect of $1 \mathrm{~km}$ had been completed. Surveys included trapping (passive searching) using baited crab traps set for a 48-hour period (see Tapley et al., 2017 for details), and active survey 
techniques, including daytime and night-time snorkeling and rock turning. Cloacal and skin swabs were taken from giant salamanders (see Tapley et al., 2017 for details), and tested for chytrid infection (Batrachochytrium dendrobatidis) using molecular methods described by Boyle et al. (2004), and for ranaviruses following Cunningham et al. (2016). During each ecological survey, physical evidence of giant salamander exploitation (e.g. bow hooks, traps, electrofishing) was also recorded if detected. Ecological surveys following our standardized methods (excluding the opportunistically surveyed Nanjiang County site) represented 2,675 person-days of passive searching and 50 cumulative person-days of active searching (Turvey et al., 2018).

We recorded environmental parameters at each site. Elevation and geographical coordinates were recorded using a GPS; water temperature, dissolved oxygen and salinity were measured using a Micro 800 Meter (Palintest, Gateshead, UK); pH was measured using a Micro $600 \mathrm{pH}$ Meter (Palintest); and ammonia (the sum of ammonia and ammonium), nitrite, nitrate, alkalinity and $\mathrm{dKH}$ (carbonate hardness) were measured with aquarium test kits (Salifert, Duiven, The Netherlands). Flow rate was measured using a locally produced unbranded flow meter, and indirect measurements of turbidity were taken using a Secchi disc. Water parameters were recorded once at each site, at the start of the first daytime survey in the middle of the stream being surveyed. All parameters were recorded either in the stream (temperature, salinity, dissolved oxygen, flow rate, turbidity) or within $15 \mathrm{~min}$ for tests that required reagents (ammonia, nitrite, nitrate, alkalinity and hardness).

We also conducted standardized questionnaire-based interviews (Tapley et al., 2017) at the 97 selected survey sites (but not at the opportunistically surveyed site in Nanjiang County), to collect local ecological knowledge on Chinese giant salamanders, including respondent sighting experience, last-sighting records and information on exploitation. All interviews were conducted in Chinese (either standard Mandarin Chinese or a local dialect), in communities situated within $1 \mathrm{~km}$ of the surveyed rivers. Full details of interview methods, including respondent selection and interview protocols, are given in Tapley et al. (2017), Chen et al. (2018) and Turvey et al. (2018).

As data were not normally distributed, we used two-tailed Mann-Whitney U tests, with Social Science Statistics (2020), to compare each of the recorded water parameter values between grouped sets of sites, as follows: (1) Sites where giant salamanders were directly detected during ecological surveys vs sites where salamanders were not detected. Because salamanders were detected in only four of the 97 randomly selected counties, data from the opportunistically surveyed site in Nanjiang County, where a giant salamander was detected, were also included in this analysis, to fulfil the minimum number of sites required for statistical analysis. This site was excluded from further analyses as it was not chosen by our standardized site selection method. (2) Sites where giant salamanders were detected during ecological surveys and/or where mean reported last-sighting date (based on lastsighting data from all respondents in each county) was within the previous 5 years vs sites where giant salamanders were not detected and where mean reported last-sighting date was $>5$ years ago.

We performed principal component analyses (PCA; Hammer et al., 2001) using varimax rotation for water parameters from three categories of sites: (1) where giant salamanders were detected directly during ecological surveys (including the opportunistically surveyed site in Nanjiang County); (2) where giant salamanders were not detected directly, but with mean last-sighting date within the previous 5 years; and (3) sites where giant salamanders were not detected directly, and with mean last-sighting date $>5$ years ago. We examined each variable that contributed moderately $(>0.50)$ to factor loadings. We also performed PCAs using varimax rotation for water parameters from sites grouped by river basin (Yellow, Yangtze, Pearl, and southeast rivers), again examining each variable that contributed moderately $(>0.50)$ to factor loadings.

\section{Results}

We recorded water parameters at all survey sites (Table 1, Supplementary Table 1). Shallow water depth at all sites precluded measurement of turbidity as the water was too clear for using a Secchi disc, and we suggest that turbidity meters are used for future studies. We detected 25 giant salamanders (Plate 1a) in four of the 97 selected survey counties and at the opportunistically surveyed site in Nanjiang: Liannan (Guangdong), 17 individuals; Jiangkou (Guizhou), 1; Lüeyang (Shaanxi), 5; Zhouzhi (Shaanxi), 1; Nanjiang (Sichuan), 1. Of these, 20 were captured and were swabbed for the amphibian chytrid fungus Batrachochytrium dendrobatidis and for ranaviruses. We did not detect the presence of either pathogen in any sample. Five animals that were recorded in Liannan (Guangdong) were not accessible as they were deep within caves. Releases of farmed giant salamanders had occurred shortly beforehand at two sites where they were detected during ecological surveys (Liannan and Lüeyang), so a proportion or all of the giant salamanders detected at these two sites could have been released animals. There was no statistically significant difference between any of the water quality parameters at sites where giant salamanders were detected by survey teams and/or had been recently seen by local respondents, and sites where they were not detected and/or from which they had recently been extirpated (Table 2). Evidence of illegal giant salamander exploitation was found at 26 of the 97 survey sites (illegal traps at 10 sites; bow hooks at six sites; evidence of electrofishing at six sites; evidence of poison fishing at nine sites; evidence of 

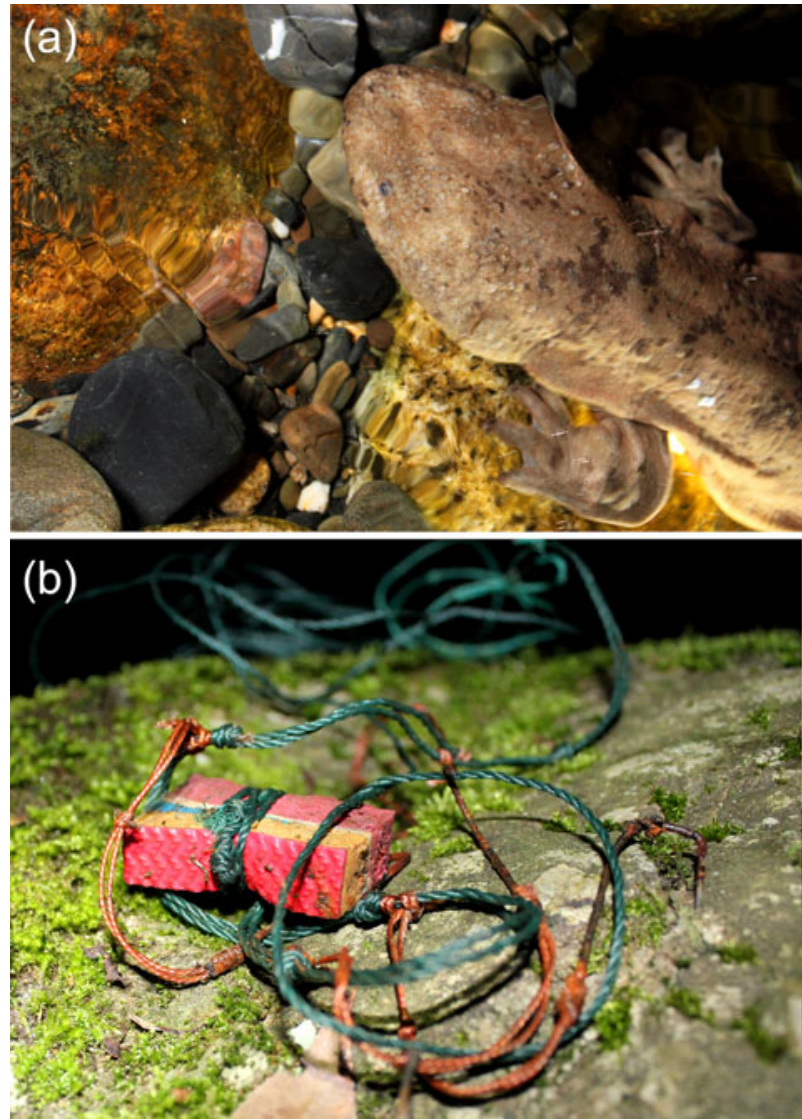

Plate 1 (a) Wild giant salamander Andrias sp. detected in Shaanxi Province, and (b) bow hooks used for poaching giant salamanders, discovered within a protected area in Guizhou Province.

multiple illegal activities at some sites), including within protected areas (Plate $1 \mathrm{~b}$ ).

A total of 2,842 people were interviewed (Supplementary Table 2). Mean reported giant salamander last-sighting dates fell within the previous 5 years in only six of the 97 counties, and did not include any of the counties in which we detected giant salamanders. Ongoing hunting by respondents was directly reported across 14 of the 16 surveyed provinces or equivalent administrative areas (Anhui, Chongqing, Fujian, Gansu, Guangdong, Guangxi, Guizhou, Hubei, Hunan, Jiangxi, Shaanxi, Sichuan, Yunnan, Zhejiang). At least one respondent in 45 of the 97 counties admitted to hunting giant salamanders $(205 / 2,842,7.2 \%)$. Furthermore, 936/2,842 respondents (32.9\%) thought that overharvesting (either by local people or by outsiders specifically hunting salamanders) was a problem for wild giant salamander populations, with $806 / 2,842(28.4 \%)$ stating that it was the top threat to wild populations, and with hunting by outsiders considered by respondents to be the primary threat to giant salamanders in three of the surveyed counties.

Between-group PCAs of water parameters across sites grouped by different giant salamander detection histories (Table 3) revealed that most of the variance $(57.61 \%)$ was 
TABLE 2 Results of two-tailed Mann-Whitney U tests comparing recorded water parameter values between grouped sets of sites: (1) sites where giant salamanders were directly detected during surveys vs sites where salamanders were not detected; and (2) sites where giant salamanders were detected during surveys and/or where mean reported last-sighting date was within the previous 5 years vs sites where giant salamanders were not detected and where mean reported last-sighting date was $>_{5}$ years ago.

\begin{tabular}{lllrl}
\hline Site grouping & Parameter & $U$ & \multicolumn{1}{l}{$z$} & P \\
\hline 1 & Temperature & 173.5 & 0.945 & 0.347 \\
& Dissolved $\mathrm{O}_{2}$ & 183.5 & -0.783 & 0.435 \\
& Salinity & 135.5 & 1.558 & 0.119 \\
pH & 206.5 & 0.412 & 0.682 \\
Ammonia & 232.5 & 0.008 & 0.992 \\
& Nitrite & 215.0 & 0.274 & 0.787 \\
Nitrate & 185.5 & -0.751 & 0.453 \\
Alkalinity & 197.0 & 0.565 & 0.569 \\
dKH & 190.0 & 0.678 & 0.497 \\
Flow rate & 201.0 & -0.465 & 0.646 \\
Temperature & 392.5 & 0.498 & 0.617 \\
& Dissolved $\mathrm{O}_{2}$ & 430.0 & 0.053 & 0.960 \\
Salinity & 298.5 & 1.613 & 0.107 \\
pH & 337.0 & 1.157 & 0.246 \\
Ammonia & 435.0 & 0.006 & 0.992 \\
& Nitrite & 400.5 & -0.403 & 0.689 \\
& Nitrate & 377.0 & -0.682 & 0.497 \\
Alkalinity & 319.5 & 1.364 & 0.174 \\
dKH & 313.5 & 1.436 & 0.150 \\
& Flow rate & 349.5 & -0.960 & 0.337 \\
\hline
\end{tabular}

explained by $\mathrm{PC} 1$ (eigenvalue $=1.67$ ), which had a strong loading for nitrate. $\mathrm{PC}_{2}$ had strong factor loadings for temperature, and explained $22.51 \%$ of the variance (eigenvalue $=0.65$ ). $\mathrm{PC}_{3}$ had strong factor loadings for $\mathrm{dKH}$, and explained $19.88 \%$ of the variance (eigenvalue $=0.58$ ). Sites where giant salamanders had recently been detected did not cluster separately from sites where they had not recently been detected (Fig. 2a).

PCA of water parameters across sites grouped by river basin (Table 4 ) revealed that most of the variance $(87.62 \%)$ was explained by $\mathrm{PC}_{1}$ (eigenvalue $=177.38$ ), which had a strong loading for nitrate. $\mathrm{PC}_{2}$ had a strong loading for temperature, but explained just $6.63 \%$ of the variance (eigenvalue $=13.42$ ). Different river basins did not form separate clusters (Fig. 2 b), although only a small number of samples were collected from the Yellow River basin.

\section{Discussion}

Our multi-year survey effort to detect Chinese giant salamanders provides a new baseline both for assessing the current status of giant salamander populations across China (Turvey et al., 2018), and also for identifying the likely drivers of their decline, knowledge of which is essential to
TABLE 3 Rotated factor loadings of principal component analysis of water parameters between sites grouped into three categories: (1) sites where giant salamanders were detected directly during surveys; (2) sites where giant salamanders were not detected directly, but with mean last-sighting date within the previous 5 years; and (3) sites where giant salamanders were not detected directly, and with mean last-sighting date $>5$ years ago. Factor loadings $>0.50$ are highlighted in bold.

\begin{tabular}{lrrr}
\hline Parameter & PC 1 & \multicolumn{1}{c}{ PC 2 } & \multicolumn{1}{c}{ PC 3 } \\
\hline Temperature & 0.268320 & $\mathbf{- 0 . 7 9 2 8 0 0}$ & -0.010920 \\
Dissolved $\mathrm{O}_{2}$ & 0.012662 & 0.388930 & 0.218570 \\
Salinity & 0.018403 & -0.010620 & 0.030002 \\
pH & 0.053618 & 0.152400 & $\mathbf{0 . 5 8 8 6 2 0}$ \\
Ammonia & 0.001699 & 0.000554 & 0.000690 \\
Nitrite & 0.001480 & 0.182130 & 0.073542 \\
Nitrate & $\mathbf{0 . 7 3 1 1 4 0}$ & -0.024350 & 0.470670 \\
Alkalinity & 0.190040 & 0.102240 & -0.207320 \\
dKH & $\mathbf{0 . 5 8 7 3 2 0}$ & 0.295780 & $-\mathbf{0 . 5 7 7 9 5 0}$ \\
Flow rate & -0.094860 & -0.255260 & -0.028040 \\
\hline
\end{tabular}

inform effective conservation management interventions. To investigate possible drivers of giant salamander decline, we explored associations between environmental factors and indicators of potential species presence across our survey sites. These indicators comprised both direct detection of Chinese giant salamanders and metrics of their possible presence based on sighting histories reported by local respondents, and local knowledge of exploitation. We chose to assess a range of indicators of giant salamander presence, to minimize the effect of potential error (either commission or omission error) in any specific signal. In addition, mean reported last-sighting date is more robust to error associated with factors such as misidentification or poor recall by nontrained respondents, compared to metrics that are more dependent upon single sighting accounts (cf. Hermoso et al., 2013; Turvey et al., 2015).

We found no significant differences in any of the water quality parameters that we tested between sites with no recent signal of giant salamanders, and those with either a direct signal (our detection) or a recent indirect signal (local respondent reports). Our PCA analyses are congruent with these findings, as sites where giant salamanders were detected either directly or indirectly do not cluster separately from other sites. This lack of any statistical differences suggests that water quality is still suitable for giant salamanders at the survey sites where the species was not detected. This conclusion is supported by the fact that we encountered diverse amphibian species assemblages, often including other aquatic salamanders, at most survey sites, which typically included amphibian genera known to be primarily associated with large intact forest patches and/or clear streams (e.g. Leptobrachium, Megophrys; Dring, 1979; Malkmus et al., 2002; Bickford et al., 2010) or that are threatened by water 

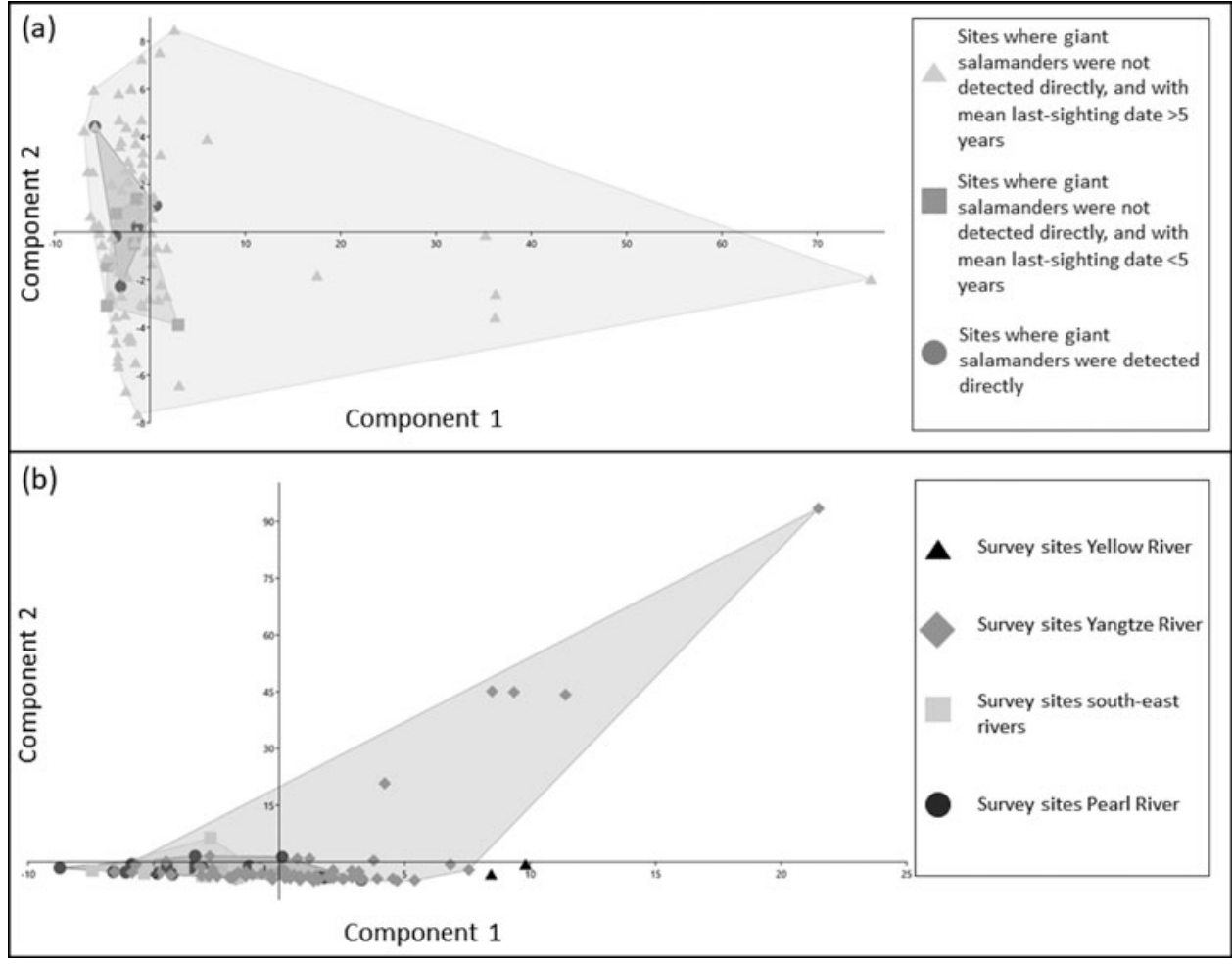

FIG. 2 Scatterplots of first and second principal components from principal component analyses of water parameters between sites, grouped by (a) giant salamander detection history, and (b) river basin. Shaded areas are the smallest convex polygons that enclose all the points in each grouped data set. pollution (e.g. Batrachuperus, Paramesotriton; Fei \& Ye, 2004; $\mathrm{Gu}$ et al., 2004; Zhao \& Yuan, 2004).

Some freshwater landscapes with historical records of Chinese giant salamanders, including the type locality for Andrias davidianus in Zhongba, Sichuan, are now heavily degraded as a result of industrial, agricultural and other anthropogenic activities, and are unable to support giant salamander populations (Dai et al., 2009). Habitat suitability modelling based on available environmental parameters, however, suggests that considerable suitable habitat for giant salamanders still exists across China (Chen et al., 2018). Our analyses of water quality parameters at a large number of sites containing such apparently suitable habitat

TABLE 4 Rotated factor loadings of principal component analysis of water parameters from sites grouped by river basin (Yangtze, Yellow, Pearl, and south-east rivers). Factor loadings $>0.50$ are highlighted in bold.

\begin{tabular}{lrrr}
\hline & \multicolumn{1}{c}{ PC 1 } & PC 2 & \multicolumn{1}{c}{ PC 3 } \\
\hline Temperature & $-\mathbf{0 . 6 2 6 4 3 0}$ & 0.203710 & $\mathbf{0 . 7 0 4 2 0 0}$ \\
Dissolved $\mathrm{O}_{2}$ & 0.029247 & 0.031494 & -0.204530 \\
Salinity & 0.014405 & 0.014093 & 0.019000 \\
pH & 0.074968 & 0.006203 & 0.040411 \\
Ammonia & 0.001651 & 0.006861 & 0.025306 \\
Nitrite & -0.011740 & 0.044073 & 0.149210 \\
Nitrate & 0.160870 & $\mathbf{0 . 9 7 2 9 6 0}$ & -0.139530 \\
Alkalinity & 0.254010 & -0.038540 & 0.182090 \\
dKH & $\mathbf{0 . 7 1 4 3 6 0}$ & -0.029020 & $\mathbf{0 . 5 8 8 4 9 0}$ \\
Flow rate & -0.006710 & -0.079450 & -0.196040 \\
\hline
\end{tabular}

did not reveal any environmental differences between sites with and without giant salamanders, further validating the habitat suitability model developed by Chen et al. (2018). Because of the ambitious scale of this study, water samples were collected only once at each site, and our surveys were undertaken during May-October over a 3-year period. Both temperature and nitrate accounted for much of the variance between sites in some of the PCA analyses. Temperature and nitrate are likely to vary between seasons, with nitrate increasing after periods of heavy rainfall (e.g. Zhu et al., 2009). We recommend that future assessment of water quality should analyse multiple water samples, with data collected at the same time of year across survey sites if possible.

Habitat loss and degradation remains a threat to giant salamander populations across China, and we did not investigate water pollutants such as heavy metals, phosphates or persistent organic pollutants, which are likely to affect giant salamanders and other amphibians (Dai et al., 2009). However, the results of our large-scale multi-year survey suggest that habitat loss is not the main driver of giant salamander population decline in China. Principal component analysis of water parameters between river basins demonstrates a high degree of similarity and there was overlap in principal components 1 and 2. Our results support the hypothesis that illegal overexploitation is an important driver of giant salamander decline in areas where suitable habitat remains. A substantial proportion of local respondents reported that hunting was a major threat to giant salamanders, and at least one respondent from each of nearly half of the 
survey sites reported hunting the species, with these figures likely to be underestimates of true hunting levels as a result of the sensitive and illegal nature of this activity. Even if respondents did not hunt giant salamanders themselves, they often reported that other people from outside their community hunted salamanders locally. The prevalence of illegal overexploitation is further demonstrated by direct evidence of ongoing poaching of giant salamanders observed by field teams at over a quarter of our survey sites. Although observed illegal fishing activities could also be targeting other aquatic species, the methods deployed are non-species specific and could result in capture, death or injury of giant salamanders.

The Chinese giant salamander complex comprises at least three species, including the recently described South China giant salamander A. sligoi (Yan et al., 2018; Liang et al., 2019; Turvey et al., 2019). The ecological survey methods deployed in this study have been successfully used to detect other cryptobranchid salamander species in both Japan and the USA (Browne et al., 2011), and therefore it is unlikely that the existence of multiple giant salamander species across our survey region confounds our results, or that different giant salamander species differ in their susceptibility to hunting. Speciation of Andrias in China was associated with uplift of the Qinghai-Tibet Plateau and geographical isolation of populations in different montane ecoregions rather than with niche differentiation (Turvey et al., 2019), and giant salamanders are likely to be generalist species with respect to their macrohabitat and microhabitat requirements. Hybrids between Chinese giant salamanders and Japanese giant salamanders (Andrias japonicus) are now invasive in parts of Japan (Fukumoto et al., 2015), and wide-scale intentional releases of giant salamanders across China has resulted in genetic homogenization of some local populations (Yan et al., 2018).

Other possible factors could also have driven the observed range-wide decline of Chinese giant salamanders. Disease is known to cause significant mortality on giant salamander farms in China (Geng et al., 2011; Meng et al., 2014) and effluent from farms is discharged into river systems without treatment across the range of Chinese giant salamanders (Cunningham et al., 2016). Furthermore, the widespread practice of releasing farmed salamanders into rivers across China is not informed by pathogen screening (Cunningham et al., 2016), and pathogen pollution could constitute a potential risk to wild populations. We were unable to quantify the potential impact of the farming industry on the health of wild populations, but the presence of diverse amphibian species communities, including other salamander species, at most of our survey sites further indicates that disease is not likely to be a primary driver of wild giant salamander population declines.

Our investigation of environmental parameters associated with giant salamander presence and absence in China provides a new evidence-base to guide conservation planning for this Critically Endangered species complex of the largest amphibians. It appears likely that giant salamander populations have been largely extirpated across our surveyed sites by poaching rather than habitat degradation. This highlights the pressing need for existing protective legislation prohibiting the hunting of giant salamanders to be better implemented and more strictly enforced, together with strict habitat protection, if Chinese giant salamanders are to persist in the wild.

Our increased knowledge of the environmental conditions under which giant salamanders occur is invaluable for informing ex situ conservation breeding programmes, which have been suggested as a necessary component of the conservation strategy for Chinese giant salamanders (Turvey et al., 2018, 2019). A robust understanding of the environmental requirements of the target species is a prerequisite for the establishment of captive breeding programmes (Michaels et al., 2014). To our knowledge, there are no existing Chinese giant salamander captive breeding programmes that can produce offspring suitable for subsequent release into the wild. Although Chinese giant salamanders have been bred to several generations on commercial breeding farms, the often unknown provenance of founding stock, presence of multiple pathogens, and often suboptimal biosecurity makes farms inappropriate for conservation breeding (Cunningham et al., 2016). Our water parameter data should therefore be used to inform the development of husbandry protocols and water quality management for Chinese giant salamander conservation breeding programmes in dedicated conservation breeding facilities in China. These data have already been used successfully for the management of an ex situ population of Andrias davidianus at the Zoological Society of London. We hope that stakeholders and decision makers in China will act upon our findings and will strengthen both in situ and ex situ conservation actions for giant salamanders while there is still time to save these remarkable species.

Acknowledgements We thank all of the field assistants for participating in surveys. Funding was provided by the Darwin Initiative (Project No. 19-003), the National Natural Science Foundation of China (31360144), Ocean Park Conservation Foundation Hong Kong, and the Zoological Society of London's EDGE of Existence programme.

Author contributions Study design, data collection, writing; BT, STT, AAC; coordination of field activities, study design, data collection: SC; study design, data collection: SO, JR, GW, FX, MW, JC; data collection: JY, ZL, HT, JW, JL, FZ, HZ, JX, TB.

\section{Conflicts of interest None.}

Ethical standards This study adhered to the code of ethics developed and endorsed by the British Sociological Foundation. All methods, including a biosecurity protocol to prevent the spread of pathogens between sites, were approved by the Zoological Society of London's Ethics Committee and comply with the Oryx guidelines on ethical standards. 


\section{References}

Bickford, D., NG, T.H., Qie, L., Kudavidanage, E.P. \& Bradshaw, C.J. (2010) Forest fragment and breeding habitat characteristics explain frog diversity and abundance in Singapore. Biotropica, 42, 119-125.

Boyle, D.G., Boyle, D.B., Olsen, V., Morgan, J.A.T. \& Hyatt, A.D. (2004) Rapid quantitative detection of chytridiomycosis (Batrachochytrium dendrobatidis) in amphibian samples using real-time Taqman PCR assay. Diseases of Aquatic Organisms, 6o, 141-148.

Browne, R.K., Li, H., Mcginnity, D., Okada, S., Wang, Z., Bodinof, C.M. et al. (2011) Survey techniques for giant salamanders and other aquatic Caudata. Amphibian \& Reptile Conservation, 5, 1-16.

BuckLey, L.B. \& Jetz, W. (2007) Environmental and historical constraints on global patterns of amphibian richness. Proceedings of the Royal Society of London B: Biological Sciences, 274, 1167-1173.

Chen, S., Cunningham, A.A., Wei, G., Yang, J., Liang, Z., Wang, J. et al. (2018) Determining threatened species distributions in the face of limited data: spatial conservation prioritization for the Chinese giant salamander (Andrias davidianus). Ecology and Evolution, 8, 3098-3108.

Cunningham, A.A., Turvey, S.T., Zhou, F., Meredith, H.M., Guan, W., Liu, X. et al. (2016) Development of the Chinese giant salamander Andrias davidianus farming industry in Shaanxi Province, China: conservation threats and opportunities. Oryx, 50, 265-273.

DAI, Q., WANG, Y. \& LiAnG, G. (2009) Conservation Status of Chinese Giant Salamander (Andrias davidianus). Chinese Academy of Sciences, Chengdu, China.

Daszak, P., Berger, L., Cunningham, A.A., Hyatt, A.D., Green, D.E. \& SPeAre, R. (1999) Emerging infectious diseases and amphibian population declines. Emerging Infectious Diseases, $5,735-748$

DrInG, J.C.M. (1979) Amphibians and reptiles from northern Trengganu, Malaysia, with descriptions of two new geckos, Cnemaspis and Cyrtodactylus. Bulletin of the British Museum (Natural History) Zoology, 34, 181-241.

Fei, L., Hu, S., Ye, S. \& Huang, Y. (2006) Fauna Sinica (Amphibia I). Science Press, Beijing, China.

FEI, L. \& YE, C. (2004) Batrachuperus pinchonii. In The IUCN Red List of Threatened Species 2004: e.T59085A11868223. dx.doi.org/10.2305/ IUCN.UK.2004.RLTS.T59085A11868223.en [accessed 19 February 2019].

Feng, X., Lau, M.W.N., Stuart, S.N., Chanson, J.S., Cox, N.A. \& Fishman, L. (2007) Conservation needs of amphibians in China: a review. Science in China, Series X, Life Sciences, 50, 265-276.

FовеS, T.M. (1995) Habitat analysis of the Ozark hellbender, Cryptobranchus alleganiensis bishopi, in Missouri. MSc thesis, Southwest Missouri State University, Springfield, USA.

FredA, J. \& DUnson, W.A. (1986) Effects of low pH and other chemical variables on the local distribution of amphibians. Copeia, 1986, 454-466.

Funumoto, S., Ushimaru, A. \& Minamoto, T. (2015) A basin-scale application of environmental DNA assessment for rare endemic species and closely related exotic species in rivers: a case study of giant salamanders in Japan. Journal of Applied Ecology, $52,358-365$.

Gallant, A.L., Klaver, R.W., Casper, G.S. \& Lannoo, M.J. (2007) Global rates of habitat loss and implications for amphibian conservation. Copeia, 2007, 967-979.

Geng, Y., Wang, K.Y., Zhou, Z.Y., Li, C.W., WAnG, J., He, M. et al. (2011) First report of a ranavirus associated with morbidity and mortality in farmed Chinese giant salamanders (Andrias davidianus). Journal of Comparative Pathology, 145, 95-102.

Grant, E.H.C., Wiewel, A.N. \& Rice, K.C. (2014) Stream-water temperature limits occupancy of salamanders in mid-Atlantic protected areas. Journal of Herpetology, 48, 45-50.

Gu, H., Geng, B. \& Yuan, Z. (2004) Paramesotriton chinensis. In The IUCN Red List of Threatened Species 2004: e.T59457A11945154. dx.doi.org/10.2305/IUCN.UK.2004.RLTS.T59457A11945154.en [accessed 19 February 2019].

Gumbs, R., Gray, C.L., Wearn, O.R. \& Owen, N.R. (2018) Tetrapods on the EDGE: overcoming data limitations to identify phylogenetic conservation priorities. PLOS ONE, 13, eo194680.

Hammer, Ø., Harper, D.A.T. \& Ryan, P.D. (2001) PAST: paleontological statistics software package for education and data analysis. Palaeontologia Electronica, 4, 1-9.

Hermoso, V., Kennard, M.J. \& Linke, S. (2013) Data acquisition for conservation assessments: is the effort worth it? PLOS ONE, 8, e 59662.

Hirschfeld, M., Blackburn, D.C., Doherty-Bone, T.M., Gonwouo, L.N., Ghose, S. \& Rödel, M.O. (2016) Dramatic declines of montane frogs in a Central African biodiversity hotspot. PLOS ONE, 11, eo155129.

IUCN (2020) Red List of Threatened Species. Version 2019-3. iucnredlist.org [accessed 7 January 2020].

Liang, G., Geng, B. \& ZhaO, E. (2004) Andrias davidianus. In The IUCN Red List of Threatened Species Species 2004: e.T1272A3375181. dx.doi.org/10.2305/IUCN.UK.2004.RLTS.T1272A3375181.en [accessed 19 February 2019].

Liang, Z.Q., Chen, W.T., Wang, D.Q., Zhang, S.H., Wang, C.R., $\mathrm{HE}$, S.P. et al. (2019) Phylogeographic patterns and conservation implications of the Endangered Chinese giant salamander. Ecology and Evolution, 9, 3879-389o.

Malkmus, R., Manthey, U., Vogel, G., Hoffmann, P. \& Kosuch, J. (2002) Amphibians and Reptiles of Mount Kinabalu (North Borneo). A.R.G. Gantner Verlag, Ruggell, Lichtenstein.

Meng, Y., Ma, J., Jiang, N., ZenG, L.B. \& XiaO, H.B. (2014) Pathological and microbiological findings from mortality of the Chinese giant salamander (Andrias davidianus). Archives of Virology, 159, 1403-1412.

Michaels, C.J., Gini, B.F. \& Preziosi, R.F. (2014) The importance of natural history and species-specific approaches in amphibian ex-situ conservation. The Herpetological Journal, 24, 135-145.

Okada, S., Utsunomiya, T., Okada, T., Felix, Z.I. \& Ito, F. (2008) Characteristics of Japanese giant salamander (Andrias japonicus) populations in two small tributary streams in Hiroshima Prefecture, western Honshu, Japan. Herpetological Conservation and Biology, 3, 192-202.

Phimmachak, S., Stuart, B.L. \& SivongXay, N. (2012) Distribution, natural history, and conservation of the Lao newt Laotriton laoensis (Caudata: Salamandridae). Journal of Herpetology, 46, 120-128.

Pugh, M.W., Hutchins, M., Madritch, M., Siefferman, L. \& GANGLOfF, M.M. (2016) Land-use and local physical and chemical habitat parameters predict site occupancy by hellbender salamanders. Hydrobiologia, 770, 105-116.

Quinn, S.A., Gibis, J.P., Hall, M.H. \& Petokas, P.J. (2013) Multiscale factors influencing distribution of the eastern hellbender salamander (Cryptobranchus alleganiensis alleganiensis) in the northern segment of its range. Journal of Herpetology, 47, 78-84.

Skerratt, L.F., Berger, L., Speare, R., Cashins, S., McDonald, K.R., Phillott, A.D. et al. (2007) Spread of chytridiomycosis has caused the rapid global decline and extinction of frogs. EcoHealth, 4, 125-134.

Social Science Statistics (2018) socscistatistics.com [accessed 10 December 2018]. 
Stegen, G., Pasmans, F., Schmidt, B.R., Rouffaer, L.O., van Praet, S., Schaub, M. et al. (2017) Drivers of salamander extirpation mediated by Batrachochytrium salamandrivorans. Nature, 544, 353-356.

Stuart, B.L., Rhodin, A.G., Grismer, L.L. \& Hansel, T. (2006) Scientific description can imperil species. Science, 312, 1137.

Tapley, B., Chen, S., Turvey, S.T., Redbond, J., Okada, S. \& Cunningham, A.A. (2017) A sustainable future for Chinese giant salamanders: Chinese giant salamander field survey manual. Technical report, Zoological Society of London. amphibians.org/ wp-content/uploads/2018/12/CGS-field-manual-final.pdf [accessed 10 December 2018].

Tapley, B., Okada, S., Redbond, J., Turvey, S.T., Chen, S., LÜ, J. \& Cunningham, A.A. (2015) Failure to detect the Chinese giant salamander (Andrias davidianus) in Fanjingshan National Nature Reserve, Guizhou Province, China. Salamandra, 51, 206-208.

Turvey, S.T., Chen, S., Tapley, B., Wei, G., Xie, F., Yan, F. et al. (2018) Imminent extinction in the wild of the world's largest amphibian. Current Biology, 28, R592-R594.

Turvey, S.T., Marr, M., Barnes, I., Brace, S., Tapley, B., Murphy, R. et al. (2019) Historical museum collections clarify the evolutionary history of cryptic species radiation in the world's largest amphibians. Ecology and Evolution, 9, 10070-10084.

Turvey, S.T., Trung, C.T., Quyet, V.D., Nhu, H.V., Thoai, D.V., TuAN, V.C.A. et al. (2015) Interview-based sighting histories can inform regional conservation prioritization for highly threatened cryptic species. Journal of Applied Ecology, 52, 422-433.

Wang, X., Zhang, K., Wang, Z., Ding, Y., Wu, W. \& Huang, S. (2004) The decline of the Chinese giant salamander Andrias davidianus and implications for its conservation. Oryx, 38, 197-202.

Welsh, JR, H.H. \& Ollivier, L.M. (1998) Stream amphibians as indicators of ecosystem stress: a case study from California's redwoods. Ecological Applications, 8, 1118-1132.

Weyrauch, S.L. \& Grubb, Jr, T.C. (2004) Patch and landscape characteristics associated with the distribution of woodland amphibians in an agricultural fragmented landscape: an information-theoretic approach. Biological Conservation, 115, 443-450.

Yan, F., LÜ, J., ZhanG, B., Yuan, Z., ZhaO, H., HuAng, S. et al. (2018) The Chinese giant salamander exemplifies the hidden extinction of cryptic species. Current Biology, 28, R590-R592.

Zhao, E. \& Yuan, Z. (2004) Paramesotriton fuzhongensis. In The IUCN Red List of Threatened Species 2004: e.T59458A11945297. dx.doi.org/10.2305/IUCN.UK.2004.RLTS.T59458A11945297.en [accessed 19 February 2019].

Zhu, B., Wang, T., Kuang, F., Luo, Z., Tang, J. \& Xu, T. (2009) Measurements of nitrate leaching from a hillslope cropland in the Central Sichuan Basin, China. Soil Science Society of America Journal, 73, 1419-1426. 